J. Lake Sci. (湖泊科学) , 2012, 24(5): 687-692

http: //www. jlakes. org. E-mail : jlakes@niglas.ac.cn

(C) 2012 by Journal of Lake Sciences

\title{
潜流湿地中微生物对三峡库区微污染水净化效果的影响”
}

\author{
刘 明, 黄 磊, 高 旭 ${ }^{* *}$, 马晓霞, 杜 刚 \\ (重庆大学三峡库区生态环境教育部重点实验室,重庆 400045)
}

\begin{abstract}
摘 要: 为了探讨潜流湿地对三峡库区微污染河水的净化效果, 在野外构建芦竹、菖蒲、空心菜和无植物 (空白) 水平潜流 人工湿地, 研究人工湿地系统中微生物基本菌群和功能菌群数量分布, 探讨污染物去除与微生物菌群种类和数量的相关 性. 结果表明: 实验湿地系统运行情况良好,植物湿地系统对各污染物指标的去除效果优于空白湿地系统; 芦竹、菖蒲、空 心菜和空白湿地系统的微生物数量均随温度的降低而减少, 其中, 植物湿地系统的微生物数量高于空白系统; 各湿地系 统的微生物数量与水质指标去除率之间的相关性较强, 在夏季, 不同人工湿地系统的细菌总数与 $\mathrm{COD}_{\mathrm{Mn}}$ 的去除率之间存 在着显著的正相关,真菌、亚硝酸细菌总数与铵氮去除率之间均存在着显著的正相关,在冬季,不同人工湿地系统的反硝 化细菌总数与总氮去除率之间存在着显著的正相关.
\end{abstract}

关键词: 水平潜流人工湿地; 微污染水; 微生物; 净化效果; 三峡库区

\section{Impact of microorganism in subsurface flow wetland on purification efficiency for slightly polluted river water in Three Gorges Reservoir Region}

\section{LIU Ming, HUANG Lei, GAO Xu, MA Xiaoxia \& DU Gang}

(Key Laboratory of the Three Gorges Reservoir Region's Eco-environments, Ministry of Education, Chongqing University, Chongqing 400045, P. R. China)

\begin{abstract}
In order to investigate the impact of microorganism in constructed wetland on purification efficiencies for slightly polluted river water in Three Gorges Reservoir Region, four horizontal subsurface flow wetlands planted with Arundo domax, Acorus calamus, Ipomoea aquatica and without plants (blank) were built in situ next to the Lushan River. The distribution of microbial basic flora and function flora in the wetlands were monitored, purification efficiencies of the constructed wetland systems were studied, and the correlation between microorganism and removal rates of pollutants were analyzed. The results showed that the experimental wetlands were adaptive to variation of inflow quality and quantity, and the removal efficiency of pollutants could be improved by planting hydrophytes. Microbial population in the planted wetlands was more than that in the blank wetland. There was positive correlation between microorganism quantity and temperature in all four wetlands, and quantity of ammonifying bacteria, nitrifying bacteria and denitrifying bacteria decreased significantly with the decline of temperature. There was conspicuous positive correlation between fungus population and removal of ammonia in summer, as well as bacteria population and removal of $\mathrm{COD}_{\mathrm{Mn}}$. It is similar positive correlation between denitrifying bacteria population and removal of total nitrogen in winter.
\end{abstract}

Keywords: Subsurface horizontal flow wetland; slightly polluted river water; microorganism; purification efficiencies; Three Gorges Reservoir Region

据统计 ${ }^{[1]}$,三峡库区有 100 多个小城镇,每年约有 $20 \times 10^{8} \mathrm{~m}^{3}$ 的生活污水及 $8 \times 10^{8} \mathrm{~m}^{3}$ 工业废水未经适 当处理而直接排人长江及次级河流,导致水质日益恶化. 作为饮用水主要来源的库区河流其污染程度也越 来越严重,难以满足人们对饮用水安全性的需要.

人工湿地作为一种典型旁路处理河流修复技术,具有生态、高效、低投资、低运转费和维护管理方便等

* 国家科技支撑计划项目 (2012BAJ25B09) 和重庆市环境保护局环保科技计划项目 (2011 第 12 号) 联合资助. $2011-$ 10-17 收稿;2011-12-19 收修改稿. 刘明,男,1986 年生,硕士研究生;E-mail :liuming0817@ 163. com.

** 通信作者;E-mail:gaoxu@ cqu. edu.cn. 
优点,已被广泛用于处理各种污水,如暴雨径流 ${ }^{[2]}$ 、农业面源废水 ${ }^{[34]}$ 、生活污水 ${ }^{[5]}$ 、工业废水 ${ }^{[6]}$ 以及管理和 控制湖泊水体富营养化 ${ }^{[7]}$. 人工湿地净化污废水的过程中,湿地基质中的微生物起着重要的作用,是污染物 质降解的基础机制. 魏成等 ${ }^{[8]}$ 对旱伞草、美人蕉、芦苇植物进行组合实验, 发现通过不同植物组合而成的湿 地系统, 可提高根际微生物群落功能多样性, 从而提高人工湿地污染物净化的效率; 龙丽珠等 ${ }^{[9]}$ 研究复合垂 直流人工湿地中发现, 特殊的水流方式使得微生物群落的数量和活性都远远高于表面流、潜流人工湿地, 复 合垂直流人工湿地的脱氮效果最好. 李科德等 ${ }^{[10]}$ 对人工模拟芦苇床根际微生物的数量进行了测定, 结果显 示, 植物根面和根际微生物数量与 $\mathrm{BOD} 、 \mathrm{COD}_{\mathrm{Mn}}$ 的去除率之间有明显的相关性, 数量越多去除率越高. 雒维国 等 ${ }^{[11]}$ 进一步研究发现,湿地中凯氏氮 $(\mathrm{KN})$ 和 $\mathrm{NH}_{4}^{+}-\mathrm{N}$ 平均去除率与湿地中的氨化细菌的分布之间没有必然联 系, 而硝化细菌的分布与湿地 $\mathrm{TN}$ 的去除率存在明显的正相关. 付融冰等 ${ }^{[12]}$ 通过测定湿地基质硝化速率,得出 硝化能力与亚硝化细菌的数量呈显著相关. 由于库区次级河流水环境治理开展较晚, 关于人工湿地系统中微 生物在处理库区污染河流的研究很少, 本实验以库区次级支流鹿山河为修复对象, 在野外构建人工湿地系统.

实验借鉴传统土壤微生物的研究方法和技术手段, 研究了人工湿地系统微生物基本菌群和功能菌群数量 分布、人工湿地系统对微污染水体的净化效果以及污染物去除与微生物菌群数量的相关性. 上述工作可为进 一步研究揭示微生物在人工湿地净化微污染水中的作用机理以及为将来湿地建造植物物种选择提供参考.

\section{1 实验材料及方法}

\section{1 实验装置}

野外装置位于三峡库区次级支流鹿山河河边, 构建 4 组水平潜流人工湿地装置 (图 1). 种植芦竹 ( Arundo domax) 、菖蒲 (Acorus calamus) 和空心菜 (Ipomoea aquatica), 并构建一个空白湿地系统 (无植物) 作为对 照, 植物种植密度为 $10 \sim 15$ 株 $/ \mathrm{m}^{2}$. 床体一端均匀布水, 原水水平流过床体. 每块湿地池体内面长 $\times$ 宽 $\times$ 高 为 $3.0 \mathrm{~m} \times 1.0 \mathrm{~m} \times 1.0 \mathrm{~m}$ (有效高度 $0.9 \mathrm{~m}$, 超高 $0.1 \mathrm{~m}$ ), 水平流湿地底面坡度为 $2 \%$, 底部和四周以水泥墙 封闭, 并进行防渗处理. 单元池分为进水区、处理区、出水区. 进水区长 $0.15 \mathrm{~m}$, 宽 $1.0 \mathrm{~m}$, 并以穿孔花墙分隔 进水区和处理区, 以防短流. 出水区长 $0.15 \mathrm{~m}$, 宽 $1.0 \mathrm{~m}$, 并以穿孔花墙分隔出水区和处理区, 均化出水水质.

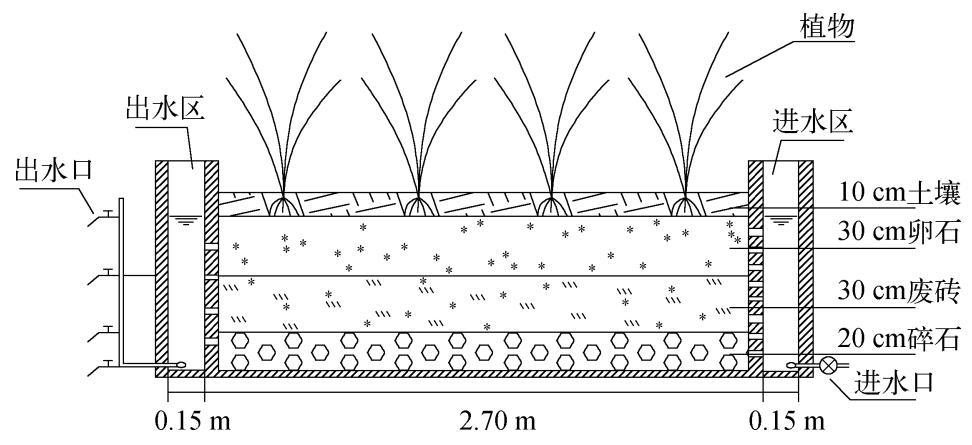

图 1 水平潜流湿地构造

Fig. 1 Construction of horizon subsurface wetland

\section{2 湿地运行与测量方法}

实验期间,各人工湿地系统采用连续进水方式,进水负荷保持在 $0.75 \mathrm{~m}^{3} / \mathrm{d}$ 左右,湿地水位控制在 $80 \mathrm{~cm}$, 水力停留时间为 $2.0 \mathrm{~d}$. 每月取样测试频率 $2 \sim 4$ 次, 采集后的水样在 $24 \mathrm{~h}$ 内分析测定. 监测水样高

表 1 人工湿地进水水质

Tab. 1 Water quality of inlet water of wetlands

\begin{tabular}{ccccc}
\hline & $\mathrm{NH}_{4}^{+}-\mathrm{N} /(\mathrm{mg} / \mathrm{L})$ & $\mathrm{TN} /(\mathrm{mg} / \mathrm{L})$ & $\mathrm{TP} /(\mathrm{mg} / \mathrm{L})$ & $\mathrm{COD}_{\mathrm{Mn}} /(\mathrm{mg} / \mathrm{L})$ \\
\hline 范围 & $0.23 \sim 1.44$ & $0.75 \sim 4.37$ & $0.049 \sim 0.107$ & $4.58 \sim 6.84$ \\
平均值 & 0.71 & 1.77 & 0.073 & 5.62 \\
\hline
\end{tabular}

锰酸盐指数 $\left(\mathrm{COD}_{\mathrm{Mn}}\right)$ 、总磷 $(\mathrm{TP})$ 、总 氮 $(\mathrm{TN})$ 和铵氮 $\left(\mathrm{NH}_{4}^{+}-\mathrm{N}\right)$, 实验设置 2 个水平. 人工湿地进水水质见表 1 . 其中, $\mathrm{COD}_{\mathrm{Mn}}$ 采用高锰酸盐酸性滴定 法测定; TN 采用碱性过硫酸钾消解 紫外分光光度法测定; $\mathrm{NH}_{4}^{+}-\mathrm{N}$ 采用 
纳氏试剂比色法测定; TP 采用过硫酸钾消解钿锑抗分光光度法测定 ${ }^{[13]}$.

\section{3 微生物数量的测定}

在夏季 (7 月) 和冬季(12月)分别对各湿地系统进行取样研究. 采样点主要分布在每个湿地系统的上层 $(5 \sim 10 \mathrm{~cm})$ 和下层 $(25 \sim 30 \mathrm{~cm})$, 按距离进水口 $5 、 150$ 和 $250 \mathrm{~cm}$ 的沿程采集样品, 且每个沿程断面分别采集 左中右 3 点的样品. 充分混匀后, 装人保鲜袋供测试用. 取样后按照文献方法进行处理 ${ }^{[14]}$, 本实验中微生物 数量为湿地系统上层和下层之和.

细菌、真菌和放线菌计数采用刮刀涂抹平板计数法, 对不同的稀释度进行 3 次重复实验, 并在恒温培养 箱中按照不同的培养条件培养,细菌、真菌和放线菌培养基分别采用牛肉膏蛋白胨培养基、虎红琼脂培养基 和改良高氏 I 号培养基;氨化细菌、亚硝酸细菌和反硝化细菌采用 MPN 稀释法,对不同的稀释度进行 4 次重 复实验,并在恒温培养箱中按照不同的培养条件培养,氨化细菌、亚硝酸细菌和反硝化细菌培养基分别采用 蛋白胨氨化培养基、改良的斯蒂芬森(Stephenson)培养基和反硝化细菌培养基.

\section{2 结果与讨论}

\section{1 人工湿地系统微生物基本菌群的数量分布}

人工湿地野外运行过程中, 污水水质 特点和大气环境, 特别是环境温度对湿地 微生物的类群和数量有一定的影响. 实验 所在地的环境温度两极化较为明显. 7-9 月人工湿地水温均高于 $24^{\circ} \mathrm{C}$, 进人 10 月后温 度开始下降, 12 月开始湿地水温降低到 $10^{\circ} \mathrm{C}$ 左右(图 2).

芦竹、菖蒲、空心菜和无植物 (对照) 湿地 系统基质的微生物基本类群数量测定结果表 明,在夏冬季节,植物湿地系统的细菌总数均 多于对照湿地系统,空心菜湿地系统的细菌 总数是对照的 3 倍多; 在冬季, 菖蒲湿地系统 的细菌总数约是对照的 2.5 倍, 不同植物湿 地系统内细菌的数量基本保持在 $10^{6}$ 数量级 (表2). 这主要是由于系统经过 2 a 长期运 行, 细菌的数量不再大幅度增加, 而是逐渐形

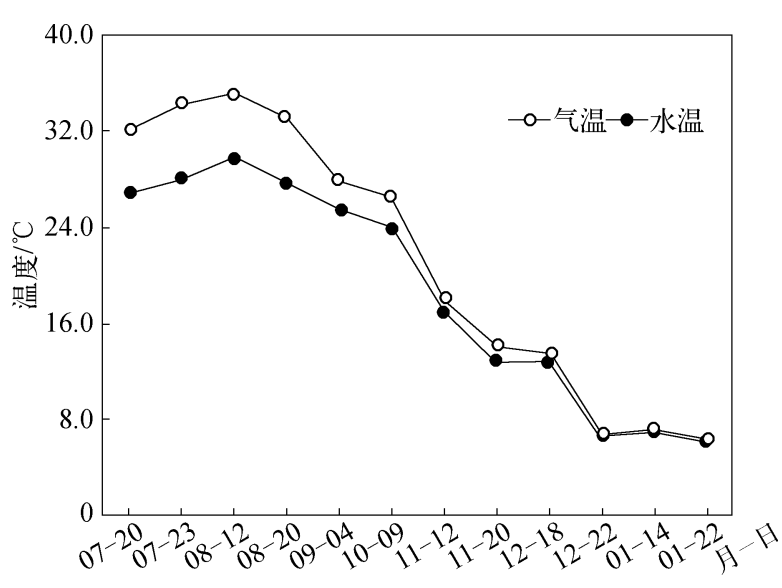

图 2 湿地环境气温和湿地水温

Fig. 2 Environmental air temperature and water temperature in wetlands 成了数量比较稳定的生物群落, 这与付融冰等对长期运行湿地的细菌数量的研究结果一致 ${ }^{[12]}$.

各人工湿地系统的真菌数量基本维持在 $10^{3} \sim 10^{4} \mathrm{cfu} / \mathrm{g}$ 干基质数量级, 比细菌和放线菌都少 (表 2 ). 这 主要是由于真菌对有机污染物的降解速度比细菌慢, 在大量可利用基质存在的情况下, 细菌在营养利用上 占据优势地位, 使真菌的繁殖过程相对受到抑制 ${ }^{[15]}$. 研究表明, 各植物的真菌数量有显著差异 $(P<0.05)$, 各湿地系统夏季的真菌数量明显高于冬季.

表 2 湿地系统微生物基本类群数量 ( $\mathrm{cfu} / \mathrm{g}$ 干基质)

Tab. 2 The abundance of microorganisms in wetlands

\begin{tabular}{|c|c|c|c|c|c|c|}
\hline \multirow{2}{*}{ 湿地类型 } & \multicolumn{2}{|c|}{ 细菌 } & \multicolumn{2}{|c|}{ 真菌 } & \multicolumn{2}{|c|}{ 放线菌 } \\
\hline & 夏季 & 冬季 & 夏季 & 冬季 & 夏季 & 冬季 \\
\hline 芦竹湿地 & $(3.14 \pm 0.16) \times 10^{6}$ & $(2.07 \pm 0.06) \times 10^{6}$ & $(6.28 \pm 0.13) \times 10^{3}$ & $(1.59 \pm 0.06) \times 10^{3}$ & $(7.07 \pm 0.17) \times 10^{5}$ & $(1.46 \pm 0.21) \times 10^{5}$ \\
\hline 菖蒲湿地 & $(3.94 \pm 0.12) \times 10^{6}$ & $(3.55 \pm 0.16) \times 10^{6}$ & $(1.37 \pm 0.08) \times 10^{4}$ & $(4.70 \pm 0.05) \times 10^{3}$ & $(6.49 \pm 0.26) \times 10^{5}$ & $(1.34 \pm 0.11) \times 10^{5}$ \\
\hline 空心菜湿地 & $(6.35 \pm 0.38) \times 10^{6}$ & $(1.66 \pm 0.03) \times 10^{6}$ & $(9.06 \pm 0.18) \times 10^{3}$ & $(5.10 \pm 0.15) \times 10^{3}$ & $(7.75 \pm 0.31) \times 10^{5}$ & $(9.79 \pm 0.20) \times 10^{4}$ \\
\hline 空白湿地 & $(2.10 \pm 0.02) \times 10^{6}$ & $(1.42 \pm 0.07) \times 10^{6}$ & $(3.84 \pm 0.31) \times 10^{3}$ & $(2.68 \pm 0.19) \times 10^{3}$ & $(4.17 \pm 0.21) \times 10^{5}$ & $(5.31 \pm 0.32) \times 10^{4}$ \\
\hline
\end{tabular}


人工湿地系统中放线菌的主要种类和优势菌属基本为好氧腐生菌, 对氧环境要求较严格. 放线菌在湿 地系统中的数量主要受基质氧化还原条件的影响. 在夏季, 有植物湿地系统的放线菌数量无明显差异; 在冬 季,芦竹和菖蒲湿地的放线菌数量明显高于对照系统. 这主要是由于芦竹具有较强的适应性,能够适应冬季 的低温环境; 而在冬季, 虽然菖蒲的地上部分枯萎,但是地下根茎能够人泥越冬 ${ }^{[16]}$,保持一定的活性.

\section{2 人工湿地功能菌群微生物数量分布}

人工湿地系统中, 氨化细菌在适宜的条件下, 将污、废水中的有机氮分解成氨氮, 氨氧化成硝酸, 是由两 类细菌经过两个阶段完成的. 第一阶段是氨在亚硝酸细菌的作用下转化为亚硝酸盐, 亚硝酸盐在硝酸细菌 的作用下转化成为硝酸盐, 再通过反硝化细菌的作用, 还原为分子态氮 ${ }^{\left[{ }^{[17]}\right.}$.

人工湿地系统基质中氨化细菌的数量为 $10^{5} \sim 10^{6}$ 数量级 (表 3). 在夏季, 芦竹和空心菜湿地系统的氨化细菌 数量明显高于对照系统; 在冬季, 菖蒲湿地系统的氨化细菌仍保持较高的数量, 其他湿地系统则无明显差异.

通常只需测定参与第一阶段的亚硝酸细菌的数量就能反映硝酸细菌数量的多葟 ${ }^{[18]}$. 人工湿地系统基质 中的亚硝酸细菌数量为 $10^{2} \sim 10^{4}$ 数量级 (表 3 ). 在夏季, 有植物湿地系统的亚硝酸细菌数量比对照湿地高出 $1 \sim 2$ 个数量级, 表明不同湿地系统的亚硝酸细菌数量有显著差异 $(P<0.05)$; 在冬季, 芦竹湿地系统的氨化 细菌数量显著高于其他湿地系统.

表 3 湿地系统功能菌群微生物数量 ( $\mathrm{cfu} / \mathrm{g}$ 干基质)

Tab. 3 The abundance of functional microorganism in wetlands

\begin{tabular}{|c|c|c|c|c|c|c|}
\hline \multirow{2}{*}{ 湿地类型 } & \multicolumn{2}{|c|}{ 氨化细菌 } & \multicolumn{2}{|c|}{ 亚硝酸细菌 } & \multicolumn{2}{|c|}{ 反硝化细菌 } \\
\hline & 夏季 & 冬季 & 夏季 & 冬季 & 夏季 & 冬季 \\
\hline 芦竹湿地 & $3.00 \times 10^{6}$ & $2.74 \times 10^{5}$ & $3.70 \times 10^{3}$ & $3.60 \times 10^{3}$ & $2.16 \times 10^{4}$ & $4.81 \times 10^{3}$ \\
\hline 菖蒲湿地 & $1.92 \times 10^{6}$ & $1.54 \times 10^{6}$ & $1.27 \times 10^{4}$ & $4.47 \times 10^{2}$ & $4.18 \times 10^{4}$ & $1.65 \times 10^{3}$ \\
\hline 空心菜湿地 & $5.40 \times 10^{6}$ & $8.21 \times 10^{5}$ & 1. $10 \times 10^{4}$ & $6.26 \times 10^{2}$ & $1.39 \times 10^{4}$ & $1.41 \times 10^{3}$ \\
\hline 对照湿地 & $1.40 \times 10^{6}$ & $4.99 \times 10^{5}$ & $2.39 \times 10^{2}$ & $1.19 \times 10^{2}$ & $4.81 \times 10^{3}$ & $3.72 \times 10^{2}$ \\
\hline
\end{tabular}

大多数反硝化菌是兼性厌氧菌, 在厌氧或者缺氧条件下将硝酸盐还原为氮气. 人工湿地系统中反硝化 细菌的数量为 $10^{2} \sim 10^{4}$ 数量级.

随着季节的变化,大气环境温度有较大的变化. 不同季节亚硝酸细菌的差异较大,这主要是由于亚硝酸 细菌是化能自养的好氧微生物, 对环境较为敏感. $\mathrm{pH}$ 、溶解氧、温度都能影响亚硝酸细菌的繁殖, 或影响其活 性. 从整体而言, 夏季的各湿地系统的反硝化细菌数量比冬季高出 1 个数量级, 这主要是由于反硝化细菌的 生长繁殖对温度较为敏感. 此外, 本研究还发现, 无论夏冬季节, 有植物湿地系统的反硝化细菌比对照湿地 高出 1 个数量级, 表明有植物和对照系统的反硝化细菌数量有极显著差异 $(P<0.01)$.

\section{3 湿地系统对污染物的净化效果}

各植物湿地系统对 $\mathrm{COD}_{\mathrm{Mn}}$ 的去除效果较为稳定. 不同湿地系统对 $\mathrm{COD}_{\mathrm{Mn}}$ 的去除能力不同 (图 3). 芦竹、 菖蒲和空心菜湿地系统对 $\mathrm{COD}_{\mathrm{Mn}}$ 的平均去除率分别为 $23.04 \% 、 23.81 \% 、 36.08 \%$; 而空白湿地系统对 $\mathrm{COD}_{\mathrm{Mn}}$ 的平均去除率为 $20.06 \%$, 略低于各植物系统.

人工湿地进水的 $\mathrm{NH}_{4}^{+}-\mathrm{N}$ 含量具有一定的波动性, 芦竹、菖蒲和空心菜湿地对 $\mathrm{NH}_{4}^{+}-\mathrm{N}$ 的平均去除率分 别为 $60.05 \% 、 66.14 \% 、 65.28 \%$. 空白湿地系统低于植物湿地系统的去除效果, 平均去除率为 $51.85 \%$. 不同 季节各湿地系统对 $\mathrm{NH}_{4}^{+}-\mathrm{N}$ 的去除效果不同,夏、冬季各湿地系统对 $\mathrm{NH}_{4}^{+}-\mathrm{N}$ 的去除效果优于秋季. 这可能与 进水的 $\mathrm{NH}_{4}^{+}-\mathrm{N}$ 含量不同有关, 从而影响系统对 $\mathrm{NH}_{4}^{+}-\mathrm{N}$ 的去除效果.

实验期间, 人工湿地进水的 $\mathrm{TN}$ 含量具有一定的波动性, 这与 $\mathrm{NH}_{4}^{+}-\mathrm{N}$ 的规律相似. 这可能与实验地地处 西部山地城镇, 年末外出务工人员的大量归来, 生活污、废水大量增加有关. 实验期间, 进水 TN 浓度超出《地 表水环境质量标准》 IV 类水体标准. 不同季节, 不同湿地系统对 TN 的去除效果也有一定的差异.

湿地进水 TP 的浓度较低从整体看,进水 TP 浓度波动性较小,基本保持在《地表水环境质量标准》 III 类 水体标准. 除芦竹湿地系统外, 其余三个湿地系统对 TP 的去除效果差异较小. 
曰芦竹湿地区菖蒲湿地区空心菜湿地区 空白湿地 - 进水
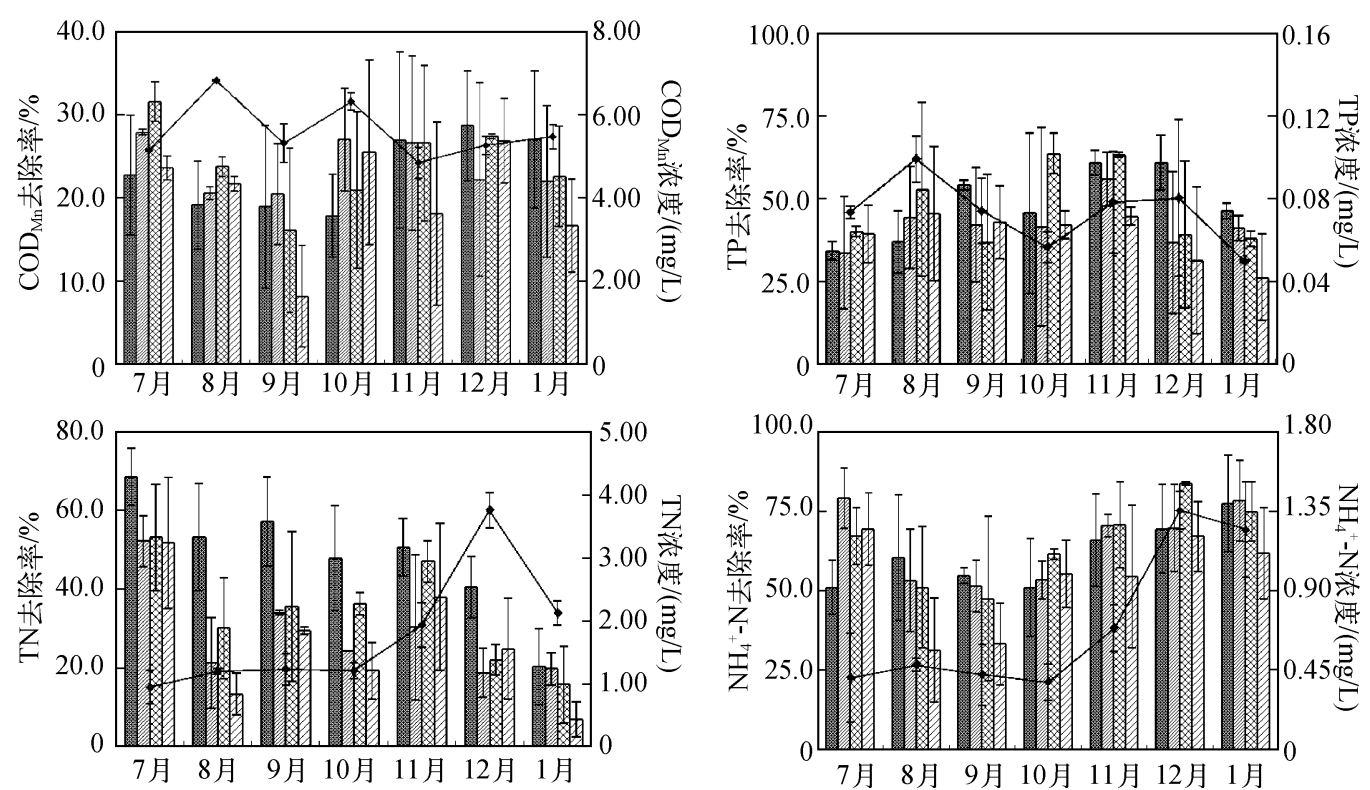

图 3 湿地对污染物的去除效果

Fig. 3 Removal efficiency of pollutants with the wetland

\section{4 湿地系统中污染物去除与微生物菌群数量相关性分析}

应用统计分析软件 SPSS 13.0 对人工湿地系统微生物数量 (细菌、真菌和放线菌) 和 $\mathrm{COD}_{\mathrm{Mn}}$ 去除率相关 性分析发现: 在夏季, 不同人工湿地系统的细菌数量总数与 $\mathrm{COD}_{\mathrm{Mn}}$ 去除率呈显著正相关 $(r=0.9791, P<$ $0.05)$, 说明微生物, 特别是细菌对 $\mathrm{COD}_{\mathrm{Mn}}$ 的去除作用显著. 这一结果与李科德等 ${ }^{[10]}$ 在芦苇床系统中的研究 结果类似;而在冬季则无明显的相关性.

通过对人工湿地系统微生物数量 (细菌、真菌、放线菌、氨化细菌、亚硝酸细菌和反硝化细菌) 和 $\mathrm{NH}_{4}^{+}-\mathrm{N}$ 去除率相关性分析, 结果发现: 在夏季, 不同人工湿地系统的真菌总数与 $\mathrm{NH}_{4}^{+}-\mathrm{N}$ 去除率呈显著正相关 $(r=$ $0.9521, P<0.05)$. 这可能是因为真菌具有强大的酶系统, 在促进纤维素、木质素、果胶等分解的同时, 能为 $\mathrm{NH}_{4}^{+}-\mathrm{N}$ 等转化或者植物吸收等方面提供丰富的酶 ${ }^{[21]}$, 从而促进湿地系统铵氮的去除. 此外, 实验还发现, 亚 硝酸细菌总数与 $\mathrm{NH}_{4}^{+}-\mathrm{N}$ 去除率呈显著正相关 $(r=0.9852, P<0.05)$. 亚硝酸细菌的多寡代表硝化细菌的多 少. 因此, 可以近似认为湿地系统中硝化细菌的总数与 $\mathrm{NH}_{4}^{+}-\mathrm{N}$ 去除率呈显著正相关. $\mathrm{NH}_{4}^{+}-\mathrm{N}$ 是硝化细菌进 行硝化作用的重要底物. 在适宜的条件下, 利用的 $\mathrm{NH}_{4}^{+}-\mathrm{N}$ 越多, 则越有利于硝化细菌的繁殖, 从而利于硝化 作用的进行 ${ }^{[19]}$.

各湿地系统对 TN 的去除效果遵循夏、秋季节优于冬季的规律; 这主要是由冬季气温迅速下降而引起 的. 冬季温度较低, 植物枯萎, 部分植物 (如空心菜) 甚至死亡, 植物对 $\mathrm{N}$ 的直接吸收能力大大降低, 同时, 湿 地系统内微生物的活动减弱,进而影响了硝化作用和反硝化作用的过程, 间接影响 TN 去除效果. 通过对人 工湿地系统微生物数量 (细菌、真菌、放线菌、氨化细菌、亚硝酸细菌和反硝化细菌) 和 TN 去除率相关性进行 分析, 结果发现: 在冬季, 不同人工湿地系统的反硝化细菌总数与 TN 去除率呈显著正相关 $(r=0.9775, P=$ $0.05)$, 而夏季则无显著相关性.

通过对湿地系统的细菌、真菌和放线菌数量与 TP 去除率相关性分析发现, 不论夏季还是冬季, 人工湿 地系统基质微生物总量与 TP 去除率均无显著的相关性. 这说明人工湿地去除磷的过程中, 主要依靠填料吸 附和部分植物吸收,微生物的作用可能不是主要因素. 


\section{3 结论}

1 ) 有植物湿地系统的微生物数量高于空白系统, 植物的存在有利于微生物的繁殖; 湿地系统的微生物 数量随温度的降低而减少,不同湿地系统减幅不同,这与不同植物的生理特性有关.

2 ) 植物湿地系统对各污染物指标的去除效果优于空白湿地系统; 在冬季,芦竹湿地对总氮、总磷去除效 果优于其他湿地.

3 ) 各湿地系统的微生物数量与水质指标去除率之间的相关性较强, 种植芦竹湿地的微生物含量相对较 多,且芦竹属于四季常青植物,适宜三峡地区水质和气候条件, 可选择芦竹湿地来处理三峡地区次级河流微 污染水体.

\section{4 参考文献}

[1] 郭劲松,杨 渊,方 芳. 西部小城镇污水处理技术评价指标体系研究. 重庆大学学报:社会科学版,2005,11(2): 12-17.

[ 2 ] Green MB, Martin JR. Constructed reed beds clean up storm overflows on small wastewater treatment works. Water Environment Research, 1996, 68(6) : 1054-1060.

[ 3 ] Braskemd BC. Factors affecting nitrogen retention in small constructed wetlands treating agricultural non-point source pollution. Ecological Engineering, 2002, 18(3): 351-370.

[ 4 ] Huang L, Gao X, Xie WD et al. Performance impact of loading rate on a multi-stage filtration system for agricultural runoff purification. Environmental Engineering and Management Journal, 2011, 10(6) : 797-801.

[ 5 ] 龚琴红, 田光明, 吴坚阳等. 垂直流湿地处理低浓度生活污水的水力负荷. 中国环境科学,2004,24(3):275-279.

[ 6 ] Vrhovšek D, Kukanja V, Bulc T. Constructed wetland for industrial wasted water treatment. Water Research, 1996, 30 (10) : 2287-2292.

～ 7 ] 张荣社,周 琪,张 健等. 潜流构造湿地去除农田排水中氮的研究. 环境科学,2003,24(1):113-116.

[ 8 ] 魏 成,刘 平. 人工湿地污水净化效率与根际微生物群落多样性的相关性研究. 农业环境科学学报, 2008,27 (6) :2401-2406.

[9] 龙丽珠,阮晓红, 赵振华. 组合人工湿地工艺微生物群落结构及脱氮效果研究. 环境污染与防治, 2006, 30 (6): 75-77.

[10］李科德,胡正嘉. 芦苇床系统净化污水的机理. 中国环境科学,1995,15(2):140-144.

[11] 雉维国. 潜流型人工湿地对氮污染物的去除效果研究 [ 学位论文]. 南京:东南大学,2005.

[12] 付融冰,杨海真,顾国维等. 人工湿地基质微生物状况与净化效果相关分析. 环境科学研究,2005,18(6):44-49.

[13］ 魏复盛. 水和废水监测分析方法:第 4 版. 北京:中国环境科学出版社,2002:223-284.

[14] 李振高,骆永明,滕 应.土壤与环境微生物研究法. 北京:科学出版社,2008:49-102.

[15] 潘 晶,张阳,孙铁珩等. 地下渗滤基质中微生物空间分布和污水净化效果. 中国环境科学, 2008, 28 (7): $656-660$.

[16] 胡秋香,赵永军,任丽君等. 潜流型菖蒲人工湿地不同 C/N 对污染物的去除率. 生态学杂志,2010,29(3):473-478.

[17] 陈 朋. 反硝化细菌的篮选鉴定及其强化处理硝酸盐废水的研究 [ 学位论文].济南: 山东大学,2009.

[18 ] Stottmeister U, Wiebner A, Kuschk P et al. Effects of plants and microorganisms in constructed wetlands for wastewater treatment. Biotechnology Advances, 2003, 22(1/2) : 93-117.

［19］周 炜,黄民生,年跃刚. 植物配置对构造湿地根际区硝化菌群及脱氮影响. 环境工程,2006,24(3):18-20. 